\title{
Study on Advanced High Voltage Capacitor and Its Applications
}

\author{
D.Edison Selvaraj \\ Department of EEE \\ Mepco Schlenk Engg., college, \\ Sivakasi \\ Tamil Nadu India
}

\author{
M.Kiruba Sankar \\ Department of EEE \\ Mepco Schlenk Engg., college, \\ Sivakasi \\ Tamil Nadu India
}

\author{
C.Dinesh Aravind \\ Department of EEE, \\ Mepco Schlenk Engg., college, \\ Sivakasi \\ Tamil Nadu India
}

\begin{abstract}
Owing to meet the advancement in electrical and electronics field modernization is common in all aspects, thus providing latest technologies on capacitors in order to take over the high voltage machineries and transmissions. These capacitors provide good effects on handling high voltage equipments and gadgets. In this paper it shoes the modern capacitor technology that holds high strength dielectrics and can withstand up to great extent in case of high voltages.
\end{abstract}

Keywords: Impregnation, Bushings, Dielectrics, Fillers, insulation oil.

\section{INTRODUCTION}

The first capacitor was used in Telephone circuits consists of interleaved sheets of paper and metal foils as dielectric material and paraffin wax was used as impregnant. They can be used only in low voltage circuits. At high voltages, failure occurs due to ionization in the voids formed in wax during cooling. The impregnant paraffin wax was replaced by petroleum jelly. In this case also, troubles occur due to the formation of voids. Hence, petroleum jelly was replaced by Mineral oil. The layers of paper and metal foil were assembled in a small case before impregnation and the case was sealed leaving a filling hole. Chlorinated oil (Penta chloro diphenyl) having pour point of $-10{ }^{\circ} \mathrm{C}$ and Mineral oil having pour point of $-45{ }^{\circ} \mathrm{C}$ can also be used as impregnant. A capacitor made with the above grade of chlorinated oil is self compensating with respect to temperature. If the capacitor was de-energized at sub-zero temperature, congealing (becoming semisolid) accompanied by void formation could occur and the capacitor damages.

Recent grades of chlorinated oil

\begin{tabular}{|c|c|}
\hline Type & Pour point \\
\hline Tetrachloro diphenyl & $-9{ }^{\circ} \mathrm{C}$ \\
\hline Trichloro diphenyl & $-18^{\circ} \mathrm{C}$ \\
\hline
\end{tabular}

At this stage stabilizers were used to improve the life properties, but now-a-days they are restricted to capacitors used on DC applications. In recent days, tests have shown that Wood pulp paper (universally known as Kraft paper) impregnated in chlorinated oil were electrically better. Operating stress in mineral oil and Chlorinated diphenyl was $13.5 \mathrm{~V} / \mu \mathrm{m}(\mathrm{rms})[130 \mathrm{KV} / \mathrm{cm}]$. Nowadays stress up to $20 \mathrm{~V} / \mu \mathrm{m}(\mathrm{rms})[20 \mathrm{KV} / \mathrm{cm}]$ is being used.

\section{REQUIREMENTS AND PROPERTIES OF THE DIELECTRICS USED IN CAPACITORS}

Complete design of a capacitor depends on the dielectric medium used. Any dielectric medium should satisfy electrically, mechanically and chemically. The dielectric should have a best combination of the following properties: Electrical strength $\tan \delta, \varepsilon$, Cost, Permissible temperature rise the dielectric should have high permittivity, because they permit to get the necessary capacitance with smaller electrode area. In general energy is stored in the dielectric.

The energy is given by,

$\mathrm{W}=1 / 2 * \mathrm{CV}^{2}$

The quality of materials necessary for the manufacture of a condenser depends on $\varepsilon$ but still more on the working intensity. The working intensity in turn depends on the electric strength of the dielectric, losses in it, etc. The working intensity should be chosen in such a way that it does not exceed the working strength of the dielectric and doesn't cause heating above the permissible temperature. Thus the cost, weight and dimension of any power capacitor depend upon the number and properties of the dielectric.

\subsection{Common Dielectric Materials Used}

\subsubsection{Mica}

It was mainly used in high frequency applications. They are rarely used due to their high cost.

2.1.2 Ceramic

This was also ruled out on economic aspects.

2.1.3 Thermoplastic Film

In this case filling the interlayer spaces with oil was difficult.

\subsubsection{Paper}

It was widely used in the high voltage capacitors. Impregnation of paper increases its dielectric strength and improves its dielectric permittivity. This is due to the fact that the innumerable pores of the paper forming 25 to $30 \%$ of the paper volume is replaced by other high quality 
insulating material having higher dielectric permittivity. Solid impregnating masses are not used, because during hardening they shrink and pores are not filled with impregnating mass, i.e. air cavity are left as such. Due to this $\varepsilon$ of the dielectric material reduces (by 10 to $15 \%$ ) and partial discharges may occur resulting in reduced life of the capacitor.

\subsection{Life expectancy of the capacitor}

The life of the capacitor will depend upon the over voltage, elevated temperature and the ageing process. For "hot spot" temperature range $=20^{\circ} \mathrm{C}$ ton $75^{\circ} \mathrm{C}$ Life expectancy is halved for every $5^{\circ} \mathrm{C}$ rise in hot spot temperature.

\section{GENERAL FEATURES OF CERAMIC CAPACITORS}

1. Minimal size, light weight.

2. Use high insulation plastic films and synthetic insulation oil.

3. Easy to install.

4. Little dielectric loss.

5. Keeps temperature stable, prolongs capacitor life.

6. Stable static capacitance.

7. Excellent manufacturing technique and strict quality control means.

8. There exists stable capacitance with little variation due to temperature and high insulation.

9. With plastic film makes its capacitance stable and durable.

10. Adopts non-polluted insulation oil which should be unharmful to human beings, animals and environment.

11. Built in discharge resistor exists, thus safety is assured.

\section{A TYPICAL POWER CAPACITOR DESIGN \\ 4.1 Method of Rating Power Capacitor Units}

When capacitors were used to improve power factor, the terms of primary corner is the magnetizing current of power load such as induction motors. The product of the magnetizing current and line voltage determines the reactive component of the load and this is usually expressed in lagging volt-ampere. Since the resulting power factor is determined by the extend that the lagging voltamperes are supplied by capacitors. It is convenient to rate the capacitor in volt-amperes and since the capacitor voltamperes are reactive, the expression VAR is used. To avoid large numbers the factor of 1000 is used giving the basis of rating, KVAR. A capacitor rated at $1 \mathrm{KVAR}$ will draw 1000VA of reactive current.

$\mathrm{KVAR}=\left(\mathrm{E}^{2} * 2 \Pi \mathrm{fC} * 10^{-6}\right) / 1000$

Where,

E- rms voltage in $\mathrm{kV}$

C-Capacitance in $\mu \mathrm{F}$

f- Frequency, cycles

The current that a capacitor will draw from the circuit is directly proportional to voltage, capacitance and frequency.

$I=2 \pi f C * 10^{-6} \mathrm{~A}$
The capacitive reactance of a capacitor is inversely proportional to frequency.

$X_{c}=\frac{1 * 10^{-6}}{2 \pi f C}$

Continuous Working Voltage: Average voltage over in any 24 hours period.

Frequency: When standard capacitors were used on frequency below 60 cycles, the kVAR would be reduced directly with frequency.

Waveform: In the design of capacitors, if the waveforms were not perfect sine wave, operating $\mathrm{kVAR}$ was higher due to the effect of harmonics.

Ambient Temperature: All power capacitor units were designed for an ambient temperature of $40 \mathrm{oC}$, but some capacitors such as those rated for $230 \mathrm{~V}$ and outdoor openmounted units may be operated ambient temperature of $50 \mathrm{oC}$.

Terminal to case rating: The terminal to case working voltage was not intended to exceed the terminal to terminal voltage.

\subsection{Design of Power Capacitor}

Consider $15 \mathrm{kVAR}, 2400 \mathrm{~V}$ capacitor unit treated with pentachlorodiphenyl and with a nominal voltage stress of $13.8 \mathrm{~V}$ fum.

$$
\begin{aligned}
& V A R=\frac{V^{2}}{X_{c}}=V^{2} \omega C \\
& \qquad \begin{aligned}
C= & \frac{V A R}{\omega V^{2}}=\frac{V A R}{2 \pi f V^{2}} \\
& =\frac{15 * 10^{2}}{2 \pi * 50 * 2400^{2}} \\
& =8.29 \mu F
\end{aligned}
\end{aligned}
$$

Adding $7.5 \%$ allowance for manufacturing variations this becomes $8.9 \mu F \times$ Higher voltage capacitors are usually made up of series connected groups with the rating of eachgroup not exceeding $1200 \mathrm{~V}$. Since the capacitor will consists of two groups in series, each group must have a capacitance $17.82 \mu F$.

If the capacitance is made up of 12 sections each $17.82 \mu F$ group will consists of 6 sections in parallel and each section must have a capacitance of $\frac{17.92}{6}=2.97 \mu F$.

The area A can be determined from the formula $A=C * T * \mathbb{K}$

Where,

A--- Total active area of the dielectric in $\mathrm{m} 2$

$$
\text { C--- Capacitance, in } \mu F \text {. }
$$

K--- Empirical factor, which includes average assembly pressure, dielectric constant fluid film and paper density. $(\mathrm{K}=0.025)$

Each section consists of seven layers of $12.5 \mathrm{~mm}$ paper.

$$
\begin{aligned}
T & =7 * 12.5=87.5 \mathrm{wm} \\
A=C * T * K & \\
& =2.97 * 87.5 * 0.025 \\
& =6.497 \mathrm{~m}^{2}
\end{aligned}
$$


Winding Sections: In winding a capacitor section two dielectric and two foils are wound up on the mandrel with one dielectric between the foils and one on the outside of the one foil, so that a foil will always be adjacent in either direction to a dielectric. Therefore the wound length of the section is one-half the total length of dielectrics.

The active width of the dielectric is the area common to both foils. Assume foil width $=22.5 \mathrm{~cm}$, Total active area $=6.497 \mathrm{~m} 2$

The length of the winding, $L=\frac{6497}{2 * 22.5 \times 10^{2}}=14.44 \mathrm{~m}$

To setup for the winding the above section, 14 rolls of paper and two rolls of foil are arranged on the mandrels. One set of seven sheets of paper is first started, then one foil, then a second set of seven sheets of paper and then a second foil. When all the paper and foils are started, the ending must precede unit $14.44 \mathrm{~m}$ for each foil.

The paper used in winding a capacitor section is wider than foil to provide adequate margins for the prevention of flashover from foil to foil. During the winding operation the winding machine is stopped to permit insertion of tinned copper strips for making contacts with the foils and providing a means of external electrical connection.

\subsection{Winding Configurations}

There are two types of windings:

1. Flat winding.

2. Cylindrical winding

The capacitor windings are manufactured by windings on a cylindrical mandrel. The windings are initially wrapped on the cylindrical mandrel. They are then removed and pressed flat or retained as such to have a cylindrical shape. The voltage of a single turn capacitor was limited due to the small thickness of the dielectric.

\subsection{Design of Different Types of Capacitors}

\subsubsection{Power Capacitors}

They are constructed preferentially with flat windings pressed into cubic packets and tightly enclosed in sheet metal housing. In this way good heat transfer is guaranteed. Also the temperature dependent expansion of the impregnating medium is taken up by the membrane effect of the housing walls. Power capacitors are required for medium voltages. Due to this the leads for the connecting terminals as well as insulation of the windings against the housings are managed well.

\subsubsection{Coupling Capacitors}

These capacitors as well as the capacitor parts of the capacitive voltage transformers are required for voltages from $110 \mathrm{kV}$ upwards and for low power ratings. They are therefore mainly built in an insulated housing type construction. Windings include flat or cylindrical type with internal series connection.

4.4.3 Impulse Capacitors

These windings must have low inductance in the arrangement of windings and at the terminals. For capacitors in impulse voltage generation, their range is greater than $200 \mathrm{kV}$. They also have an insulated housing. Impulse capacitors for low inductance capacitive energy storage must be built with coaxial or strip conductor terminal and current return via housing.
In this type there is short duration over shooting of the inception voltage. The impulse condenser are used as stores of energy in laboratory impulse voltage and current generators.

Operating Field Strength (usually $\mathrm{E}=(80$ 100) $V / \mathrm{wm})$. With long life span--- $(30-40) \mathrm{kV} / \mathrm{\mu m}$. With limited life span--- up to $100 \mathrm{kV} / \mathrm{mm}$. The sudden discharge of a HV capacitor constitutes high mechanical stressing of the windings and their connections, In the above figure the electrostatic force can be calculated using the energy equation,

$F^{v}=\frac{1}{2} \epsilon_{0} \epsilon_{\mathrm{y}} \mathbb{E}^{2}$

For $\mathrm{E}=75 \mathrm{~V} / \mathrm{wm}, \epsilon_{\mathrm{y}}=4.2----F^{v}=10^{5} \mathrm{~N} / \mathrm{m}^{2}=1 \mathrm{bar}$

For a sudden discharge this pressure, withstood earlier in the winding vanishes very abruptly. For an oscillating discharge, pressure oscillations at twice the discharge frequency occur, and the consequence is a strong mechanical alternating stress on the thin metal and insulating foils.

The electromagnetic forces make it essential that the construction of the winding connections should be of high mechanical quality and strength. To keep the magnetic fields by the discharge current ' $i$ ' at a minimum, the impulse capacitors must have direct axial current leads at each winding of the metal foils if possible.

Impulse capacitors are subject to operational oscillatory voltages as shown below.

$\mathrm{U}_{0^{---}}$charging voltage

k----oscillatory factor

For the stresses so produced the oscillatory factor $\mathrm{k}$ is of great significance .In Impulse capacitors for plasma physics measurements, it is usual to aim life time of about $\mathrm{N}=10000$ discharges for $\mathrm{k}=0.8$.

The following graph gives an idea of the relation between operating field strength and the discharge number ' $N$ ' expected up to breakdown.

The above graph was based on the oil impregnated paper windings for $\mathrm{k}=0.8$.for $\mathrm{k}=5$ one may expect 4 times the number of discharges to breakdown. Also a decrease in operating field strength by $10 \%$ also permits anticipation of 4 times longer life time. By using castor oil further increase in life time is got.

\subsubsection{Dc Capacitors}

These capacitors are usually charged with a unidirectional voltage and the stored energy is suddenly released through a switch or gap to provide a high current pulse. They have short life $\left(10^{6}\right.$ discharges $)$ and hence possible to operate at high stress (even above inception level).

Advantage of high stress----The size and hence the cost is reduced.

Disadvantage of high stress---- High stress may cause failure of too many windings, resulting in economic loss.

Material Used: Aluminium loaded paper.

Advantages of Aluminium loaded paper:

It absorbs the ionic impurities in the impregnant and makes them inert to the electrical stress and high temperature. It absorbs the decomposition products generated due to electrochemical and thermal degradation.

Impregnant: Cleaned castor oil

Castor oil has the same dielectric strength as mineral oil. 


$$
E=4.5-4.7
$$

The dielectric constant of the impregnated paper is increased to $5.5-6.0$. As a result the volume and weight of the capacitor is reduced.

Operating field Strength: With long life span: $(25$ - 40) $\mathrm{kV} / \mathrm{mm}$. With limited life span: up to $100 \mathrm{kV} / \mathrm{mm}$

Smoothing capacitors (mineral impregnated paper): (80 100) $\mathrm{V} / \mathrm{wm}$

When askarel impregnated paper windings are subjected to direct voltage testing the following data was got.

\begin{tabular}{|c|c|c|c|}
\hline $\begin{array}{c}\text { No. of } \\
\text { layers }\end{array}$ & 2 & 3 & 4 \\
\hline $\mathrm{E}_{\mathrm{d}}$ & 100 & 170 & 230 \\
\hline
\end{tabular}

Pulse Repetition Rate: Discharge repetition rate of the capacitors of five to six discharges per minute can usually be achieved with only a moderate increase in temperature. Increasing the repetition rate would lead to higher internal temperature. The loss factor also increases with temperature and thermal instability could be reached.

Protection: The capacitors usually discharge into low impedances and hence no fuses re fitted internally but in small banks the fuses are used externally. Discharge resistances are not fitted because of the excessive charging current required.

\subsubsection{Ac Capacitors}

Material Used: Paper which is mostly impregnated with synthetic polarized liquids of the type of pentachloro diphenyl with permittivity nearly 5 i.e., about 2 times larger than the mineral oil used. By additional special cleaning techniques it is possible to get synthetic polarized liquids with $\tan \delta=(0.003-0.006)$. The weight gets reduced by (35-40)\% of the mineral oil impregnated capacitors.

Operating Field Strength: At 50 cycles, prolonged action of the voltage and absence of over voltages--- (12-14) k $\mathrm{V}_{\mathrm{rms}} / \mathrm{mm}$. With the possibility of occurrence of internal over voltages--- (8-9) $\mathrm{kV}_{\text {rms }} / \mathrm{mm}$.

With the possibility of occurrence of internal and external over voltages--- (7-8) $\mathrm{kV}_{\text {rms }} / \mathrm{mm}$.

At a frequency of $0.1-10 \mathrm{kC}$ prolonged application of voltage and natural cooling--- (3-6) $\mathrm{kV}_{\mathrm{rms}} / \mathrm{mm}$ and with water cooling--- $(8-10) \mathrm{kV}_{\text {rms }} / \mathrm{mm}$.

Power Capacitors, (I) askarel impregnated paper--- $\mathrm{E}=(15-$ 20) $\mathrm{V} / \mathrm{wm}$

(ii) askarel impregnated paper/foils--- $\mathrm{E}=(35-40) V / \mathrm{cm}$

Measuring and Coupling capacitors, mineral oil impregnated paper--- $\mathrm{E}=(10-15) V / \mu m$

Paper Thickness: (10-25)wm

Windings: Flat, cylindrical. Both series and parallel connection exist. The type of connections varies based on the operating voltage. The following table illustrates the combination for a pack of 12 windings.

\begin{tabular}{|c|c|c|}
\hline $\begin{array}{c}\text { Series } \\
\text { windings }\end{array}$ & Parallel & $\begin{array}{c}\text { Operating } \\
\text { Voltage }\end{array}$ \\
\hline 1 & 12 & 800 \\
\hline 2 & 6 & 1600 \\
\hline 3 & 4 & 2400 \\
\hline 4 & 3 & 3200 \\
\hline
\end{tabular}

\begin{tabular}{|c|l|l|}
\hline 6 & 2 & 4800 \\
\hline 12 & 1 & 9600 \\
\hline
\end{tabular}

Fuse Protection: Internal and External fuses. External fuses only

Effect of Internal fuses in:,

(i)Mineral Oil Impregnated Capacitors- Faulty windings are isolated locally and they permit the continued operation of capacitor banks with little inference to operational needs.

(ii)Chlorinated Impregnants-Internal fusing causes carbonization and decomposition into undesirable products and reduces the life of the unit.

Due to the disadvantages of internal fuses. External fuses are mostly preferred.

\section{KEY COMPONENTS FOR A COMPLETE DESIGN}

There are four key components:

1. Insulation to Case

2. Discharge resistance

3. Bushing

4. Wicking Effect

\subsection{Insulation to Case}

Layers of paper are wrapped around the capacitor. Thickness of the layer depend on impulse withstand level.

\subsection{Discharge resistance}

It was required for the safe handling of power frequency capacitors after de-energization. Power loss is less in the discharge resistance when compared to the dielectric loss in capacitor. Increase in temperature is also not high due to this resistance.

\subsection{Bushings}

They should operate satisfactorily both in dry and wet conditions.

\subsection{Wicking Effect}

It means to the uniform distribution of the impregnant (oil) in the dielectric. This distribution mainly depends on the material used (i.e., its absorption capability). In order to achieve excelled wicking effect a fibrous surface capacitor tissue paper sandwiched between aluminum foil and polypropylene film. This layer configuration helps in complete drying and void free impregnation. Thus the capacitor is electrically robust and has long life.

\section{COMPARISON OF DIFFERENT CAPACITORS}

\subsection{Comparison between Paper Impregnation with Mineral Oil and Chlorinated Diphenyls}




\begin{tabular}{|l|l|}
\hline \multicolumn{1}{|c|}{$\begin{array}{c}\text { Mineral Oil } \\
\text { Impregnation }\end{array}$} & \multicolumn{1}{c|}{$\begin{array}{c}\text { Chlorinated Diphenyl } \\
\text { (askarel) }\end{array}$} \\
\hline $\begin{array}{l}\text { (i) Used in measuring } \\
\text { and coupling capacitors. }\end{array}$ & $\begin{array}{l}\text { (i) Used in power } \\
\text { capacitors }\end{array}$ \\
\hline $\begin{array}{l}\text { (ii) } \epsilon_{y}=4.2 \text { tan } \delta<0.2 \% \\
\text { The power density in this } \\
\text { case is more than the } \\
\text { mineral oil impregnation. }\end{array}$ \\
$\begin{array}{l}\text { (iii) With persisting } \\
\text { overstepping of the } \\
\text { inception voltage wax } \\
\text { formation and ultimate } \\
\text { breakdown at the edges } \\
\text { should be expected. }\end{array}$ & $\begin{array}{l}\text { (iii) With askarel on } \\
\text { account of the danger of } \\
\text { HCl acid formation at } \\
\text { the metal edges, special } \\
\text { attention should be paid } \\
\text { to ensure that the } \\
\text { inception voltage is not } \\
\text { exceeded even for short } \\
\text { duration. }\end{array}$ \\
\hline
\end{tabular}

\subsection{Compare Single Layer MPP (Metalized Polypropylene) and Two Layer (Film, Paper + Foil) Capacitors}

\begin{tabular}{|l|l|}
\hline \multicolumn{1}{|c|}{ Single layer (MPP) } & \multicolumn{1}{|c|}{$\begin{array}{c}\text { Two layer - film + } \\
\text { paper + foil }\end{array}$} \\
\hline $\begin{array}{l}\text { (i) quantity of } \\
\text { dielectric material } \\
\text { used is only 12\% to } \\
22 \% \text { compared to } \\
\text { two layer film + } \\
\text { paper + foil design. } \\
\text { dielectric material } \\
\text { used is more than 4.5 } \\
\text { to 8 times compared } \\
\text { to single layer MPP } \\
\text { design }\end{array}$ \\
\hline $\begin{array}{l}\text { (ii) Output of } \\
\text { capacitor will go on } \\
\text { reducing with time. }\end{array}$ & $\begin{array}{l}\text { (ii) Output of } \\
\text { Capacitor will } \\
\text { remain steady over a } \\
\text { period of time }\end{array}$ \\
\hline $\begin{array}{l}\text { (iii) The power factor } \\
\text { will go on reducing } \\
\text { hence increasing the } \\
\text { maximum demand. }\end{array}$ & $\begin{array}{l}\text { (iii) the power factor } \\
\text { and maximum } \\
\text { demand will remain } \\
\text { steady at the } \\
\text { corrected value. }\end{array}$ \\
\hline $\begin{array}{l}\text { (iv) Frequent } \\
\text { replacement is } \\
\text { necessary to maintain } \\
\text { the power factor. }\end{array}$ & $\begin{array}{l}\text { (iv) Working life is } \\
\text { long. }\end{array}$ \\
\hline
\end{tabular}

\begin{tabular}{|l|l|}
\hline (v) Initial cost is & (v) Initial cost is high \\
much low, but short & but with very long \\
working life and very & dependable working \\
costly. & life ultimately proves \\
& very economical.
\end{tabular}

\section{CONCLUSION}

Thus, the use of intensive techniques for using advanced capacitors for high voltage transmissions and machineries were illustrated above and their special techniques were also shown above. The capacitors are shown are mostly used for high efficient energy transmissions and latest requirements to meet energy needs and high voltage withstanding capacities and the bushing technology shown are of highly efficient and proves of proper efficient transmissions. Using appropriate technology is the smartness on latest trends HV capacitors provide enough needs to make over the faults were others does.

\section{ACKNOWLEDGEMENT}

The authors express their sincere gratitude to the almighty God and the Lord Jesus Christ for His blessings for this research. The authors also express their sincere thanks to the Department of Mechanical Engineering and Physics, Mepco Schlenk Engineering College, Sivakasi, India and the Division of High Voltage Engineering, College of Engineering, Guindy, Anna University, Chennai, India for the sample preparation and testing of samples.

\section{REFERENCES}

[1].DR Buehler, Exploratory Research on the Phenomenon of the Movement of High Voltage Capacitors. Journal of Space Mixing, 2004; Patrick G. Bailey, "Overview Of Antigravity ... Robert Stirniman, Electrogravitics

[2] Electrostatics \& High Voltage Links ... from (ESD Journal); High-voltage Handbook · Matweb (capacitor dielectric search!)

[3] Apparatus Bushing Reference Book, Gen- eral Electric Co., Bulletin GET- 2525. NEMA Publication No. 1071964, Reaffirmed by NEMA 1976.

[4] High voltage electrochemical double layer capacitors using conductive carbons as additives. M.S. Michael,; S.R.S. Prabaharan.

[5] Design, Analysis and Construction of a High Voltage Capacitor .Author: Nathan S. Tyler. Approved by: Alexander L. Julian.

[6] High power \&performance capacitor by Alexpokryvailo,Costal carp and cliffard scallpati on vol. 38, no.10 IEEE OCT 2010.

[7] Three-Dimensional Heat Transfer Analysis of PinBushing System With Oscillatory Motion: Theory and 
International Journal of Science and Engineering Applications (IJSEA)

Volume 1 Issue 2, 2012, ISSN - 2319-7560 (online)

Experiment Author(s): Jun Wen, Mem. ASME and M. M.

Khonsari, Dow Chemical Endowed Chair in Rotating

Machinery, Professor, Fellow ASME

Department of Mechanical Engineering, Louisiana State

University, 2508 Patrick Taylor Hall, Baton Rouge, LA

70808

[8] Bushing for power transformer by James .B

[9] Electrical Machines, Second Edition,Smarajit Ghos,

Pearson Education India,March 12, 2012. 